\title{
Perancangan Sistem Informasi Berbasis Website Sebagai Salah Satu Media Promosi Pada Perusahaan
}

\section{Design Of Web-Based Information Systems As Promotional Media For Companies}

\author{
Jerio Madre*1), H. Yudi Sukmono2), dan Suwardi Gunawan ${ }^{3)}$ \\ Program Studi Teknik Industri, Fakultas Teknik. Universitas Mulawarman.
}

Diterima: Juli 2021; Disetujui: November 2021; Dipublikasi: November 2021;

*Coresponding author : jeriomadre@gmail.com

\begin{abstract}
Abstrak
PT XYZ yang berada di kota bontang, saat ini perusahaan ini melakukan pemasaran dan promosi secara metode konvensional yakni dengan koneksi mulut ke mulut serta melakukan promosi sesama rekan usaha sehingga hanya sedikit yang mengenal dan mengetahuinya. Dengan website perusahaan bisa memberikan informasi mengenai produk/layanan yang diberikan secara lengkap. Perkembangan ilmu pengetahuan dan teknologi yang sangat pesat menjadikan teknologi informasi menjadi suatu hal yang penting dalam kehidupan sehari-hari. Perancangan sistem informasi perusahaan berbasis website dilakukan dengan metode Prototype mulai dari melakukan analisa kebutuhan pengguna, Melakukan perancangan sistem menggunakan beberapa tools yakni Use Case Diagram, Context Diagram, Data Flow Diagram, dan tabel database. Tahap selanjutnya dilakukan perancangan desain User Interface. Kemudian pengkodingan website menggunakan PHP, Codeigniter 3 dan Bootstrap 4 serta aplikasi MySQL sebagai databasenya. Kemudian dilakukan pengujian sistem menggunakan metode Black box testing dan SEO website analyzer. Terakhir dilakukan evaluasi dan penyerahan kepada perusahaan dalam bentuk template website yang siap untuk digunakan. Dengandirancanganya sebuah website sesuai dengan kebutuhan perusahaan diharapkan dapat meningkatkan jumlah pelanggan dan membantu mempublikasikan produk dan jasa secara luas melalui jaringan internet.
\end{abstract}

Kata Kunci: Sistem Informasi, Promosi, Context Diagram, Data Flow Diagram, Use Case Diagram, Prototype, Blackbox.

\begin{abstract}
PT XYZ, which is located in the city of Bontang, is currently conducting marketing and promotions using conventional methods by means of word of mouth connections and promoting fellow business partners so that only a few know and know about it. With the company's website, you can provide complete information about the products/services provided. The rapid development of science and technology makes information technology an important thing in everyday life. The design of a website-based company information system is carried out using the Prototype method, starting from analyzing user needs, designing systems using Use Case Diagrams, Context Diagrams, Data Flow Diagrams, and database tables. The next stage is designing the User Interface design. Then coding the website using PHP, Codeigniter 3 and Bootstrap 4 as well as the MySQL application as the database system. Then the system is tested using the Black box testing method and SEO website analyzer. Finally, an evaluation and submission to the company is carried out in the form of a website template that is ready to be used. By designing a website according to the company's needs, it is expected to increase the number of customers and help publicize products and services widely through the internet network.
\end{abstract}

Keywords: Information System, Use Case Diagrams, Context Diagrams, Data Flow Diagrams (DFD), Prototype Method, Blackbox.

How to Cite: Madre, Jerio, H. Yudi Sukmono, dan Suwardi Gunawan (2021). Perancangan Sistem Informasi Berbasis Website Sebagai Salah Satu Media Promosi Pada Perusahaan. JIME (Journal of Industrial and Manufacture Engineering). 5(2): 122 - 120 


\section{PENDAHULUAN}

Perkembangan ilmu pengetahuan dan teknologi yang sangat pesat menjadikan teknologi informasi menjadi suatu hal yang penting dalam kehidupan sehari-hari. Perkembangan teknologi internet sekarang ini lebih banyak berkembang ke arah user-friendly yang artinya semakin mempermudah pemakai dalam memahami serta menjalankan fungsi dari internet tersebut. Dengan adanya internet segala kegiatan ataupun transaksi dapat dilakukan tanpa dibatasi oleh ruang dan waktu internet merupakan salah satu media pemasaran yang bersifat global dengan akses 24 jam tanpa henti sehingga dapat dimanfaatkan sebagai media promosi (Rianto, 2018).

Menurut data dari lembaga asosiasi penyelenggara jasa internet indonesia (APJII), Pada tahun 2018 diketahui bahwa penetrasi pengguna internet di indonesia adalah sebesar $64,8 \%$ dari jumlah penduduk di indonesia atau sebanyak 171,17 juta dari total populasi penduduk indonesia yaitu 264,16 juta orang. Jumlah ini meningkat sebanyak $10,2 \%$ atau sebanyak 27,91 juta orang dari tahun 2017 dimana pengguna internet pada tahun 2017 adalah 143,26\% dari 262 juta penduduk indonesia (APJI, 2018).

PT XYZ adalah salah satu perusahaan yang berdiri sejak 12 November 2018 di kota Bontang dimana saat ini PT XYZ sedang dalam proses pengembangan usaha yang bergerak dalam beberapa bidang pengadaan barang dan jasa bagi konsumen seperti, penyewaan mobil angkutan antarkota dalam provinsi (AKDP), Distributor bahan bakar padat, cair dan gas, distributor kapur. Kegiatan pemasaran dan promosi yang dilakukan oleh PT XYZ saat ini masih kurang dikelolah dengan maksimal. Dalam pelaksanaan pemasaran dan promosinya masih dilakukan secara konvensional.

\section{METODE PENELITIAN}

Metode penelitian ini terdiri dari beberapa tahapan. Tahap pertama adalah pendahuluan, Tahap ini merupakan tahapan persiapan sebelum dilakukannya penelitian yang berguna untuk memfokuskan penelitian serta menetapkan metode yang digunakan. Pada tahap ini dilakukan Studi pendahuluan yang merupakan tahap awal sebelum melakukan penelitian. Studi pendahuluan dilakukan dengan observasi dan studi literatur yang berkaitan dengan promosi dan sistem informasi, kemudian mengidentifikasi masalah dengan tujuan untuk mengidentifikasi indikatorindikator yang berkaitan dengan perancangan sistem informasi, merumuskan permasalahan yang akan dibahas dalam penelitian ini, penentuan tujuan dan batasan masalah untuk menjaga agar penelitian yang dilakukan tidak melebar dari tujuan yang sudah seharusnya.

Tahap kedua adalah pengumpulan data, pada tahapan ini dilakukan pengumpulan data yang berhubungan dengan penelitian ini. Data yang dikumpulkan akan digunakan sebagai masukan pada tahap selanjutnya. Pada tahapan ini data yang dikumpulkan adalah data yang berhubungan dengan penelitian dengan 2 jenis data yang digunakan yaitu data primer dan data sekunder. Dalam memperoleh data primer pada penelitian ini adalah dengan melakukan wawancara dan kegiatan tanya jawab dengan manajer 
dan beberapa karyawan perusahaan, data sekunder yang dibutuhkan seperti profil perusahaan, struktur organisasi, produk dan layanan perusahaan. Data sekunder didapatkan dari internet, catatan perusahaan, jurnal dan penelitian sejenis.

Tahap ketiga adalah pengolahan data dan analisa. Dalam penelitian ini metode yang digunakan adalah mengikuti model pengembangan sistem metode prototype karena lebih menghemat waktu dalam pengembangan sistem, pengembang dapat bekerja lebih baik dalam menentukan kebutuhan pelanggan, penerapan menjadi lebih mudah karena pemakai mengetahui apa yang diharapkan. Metode Prototype, dimulai dengan mengumpulkan kebutuhan. Pengembang dan klien bertemu guna mendefinisikan obyektif keseluruhan dari perangkat lunak, mengidentifikasikan segala kebutuhan dari segi input dan format output serta gambaran interface, kemudian dilakukan perancangan cepat. Dari hasil perancangan cepat tersebut nantinya akan dilakukan pengujian dan evaluasi (Pressman, 2002).

Tahap terakhir adalah tahap penutup dalam penelitian ini adalah penyusunan kesimpulan berdasarkan hasil dari penelitian. Kesimpulan yang disusun akan menjawab tujuan dari dilakukannya penelitian ini. Selanjutnya, setelah diberikan kesimpulan maka akan diberikan saran baik untuk penelitian maupun untuk perusahaan.

\section{HASIL DAN PEMBAHASAN}

A. Analisa Sistem

Pada tahapan ini akan menguraikan beberapa hal yang berkaitan dengan ruang lingkup pekerjaan yang nantinya dibutuhkan untuk mengambil keputusan dalam pembuatan sistem informasi ini.

1. Analisis Sistem yang Berjalan.

Aliran sistem informasi yang berjalan bertujuan untuk mengetahui bagaimana terjadinya proses kegiata dalam operasional dan juga untuk mengetahui masalah-masalah yang ada serta kelemahan-kelemahan pada sistem yang sedang berjalan sekarang ini. Sistem yang lama atau yang saat ini berjalan adalah sistem dimana saat ada konsumen atau calon pelanggan ingin mendapatkan informasi layanan dan melakukan pesanan harus melalui pemilik perusahaan untuk berdiskusi tentang produk, mencetak profil perusahaan, negosiasi harga, melengkapi berkas dan sebagainya. Proses ini terkesan lama dan cukup ribet bagi konsumen yang hanya sekedar mencari informasi perusahaan saja.

\section{Analisis Sistem yang diusulkan}

Sistem yang diusulkan diharapkan dapat memberikan gambaran yang jelas dalam pembuatan sistem informasi yang dapat membantu proses penjualan dan memperluas konsumen. Analisis sistem yang diusulkan digambarkan dalam bentuk flowchart yang dapat menjelaskan proses aliran data sehingga menghasilkan informasi yang diinginkan. Adapun rencana kegiatan yang diusulkan adalah untuk meringkas proses yang sama dalam setiap melakukan pemesanan layanan pada PT XYZ dimana proses yang diusulkan untuk menjadi bahan dalam pembuatan sistem informasi ini adalah mulai dari proses mencari informasi perusahaan hingga proses pengajuan PO (Purchase Order). 
Jerio Madre, H. Yudi Sukmono, dan Suwardi Gunawan. Perancangan Sistem Informasi Berbasis Website Sebagai Salah Satu Media Promosi Pada Perusahaan

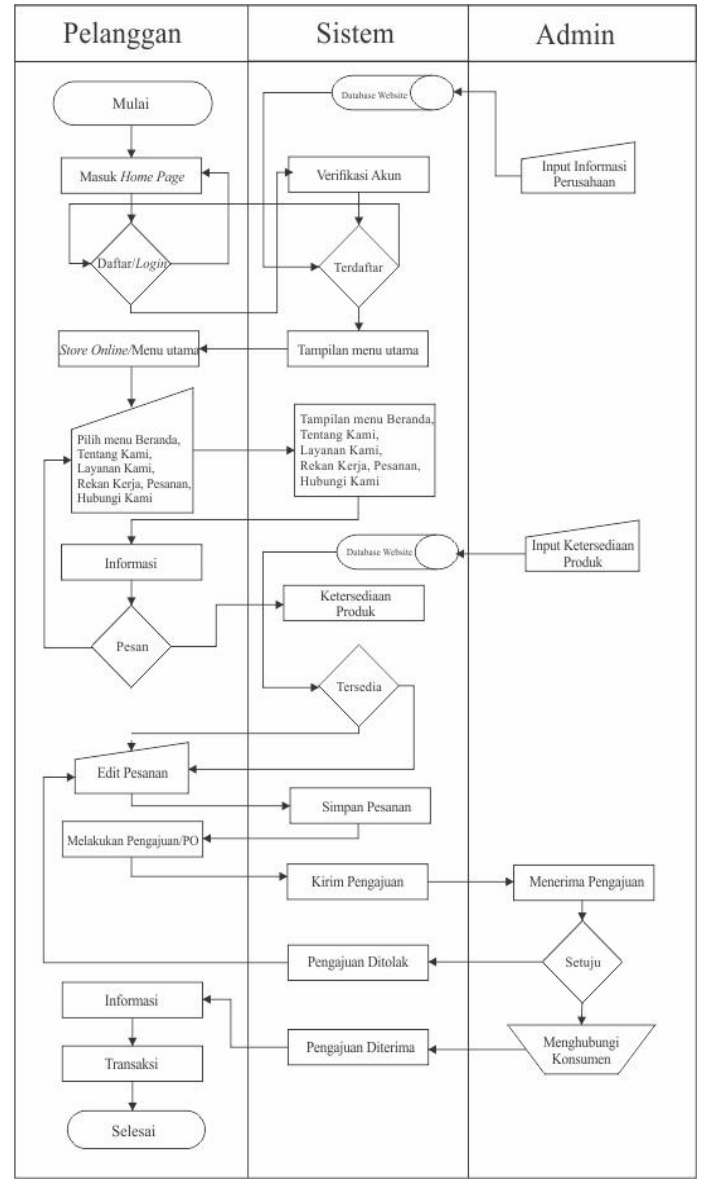

Gambar 1. Flowchart usulan system informasi

3. Analisis Kebutuhan Fungsional

a) Admin

Admin memiliki hak untuk mengubah isi dari website, menerima informasi pesanan, melihat data-data konsumen dan data pesanan.

b) Konsumen

Konsumen memiliki hak untuk melihat informasi website, melakukan registrasi untuk melakukan pesanan.

4. Analisis Kebutuhan Non-Fungsional

a) Perangkat Lunak

Perangkat lunak yang dibutuhkan:

1). Bootstrap 4,

2). MySQL,

3). XAMPP Server, dan

4). Codeigniter 3. b) Perangkat Keras

Perangkat keras yang digunakan:

1). Laptop Acer A315-41-R97I, Processor AMD RyzenTM5 2500U with Radeon Vega Mobile Gfx 2.00 GHz, 8 GB DDR4 Memory Ram, dan Penyimpanan 1000 GB HDD.

B. Perancangan dan Desain Sistem.

Perancangan sistem berguna sebagai gambaran awal sistem yang akan dibuat. Perancangan ini terbagi menjadi 4 bagian yaitu memodelkan alur proses sistem dengan Context Diagram, Data Flow Digram (DFD), use case Diagram, pembuatan rancangan database, membuat rancangan berupa prototype rancangan tampilan website berdasarkan kebutuhan dan tahap terakhir adalah implementasi sistem berupa pengkodingan.

\section{Context Diagram}

Diagram konteks adalah diagram yang menggambarkan bagian besar dari aliran arus data Sistem Website. Konteks Diagram PT XYZ dapat dilihat pada gambar 2 .

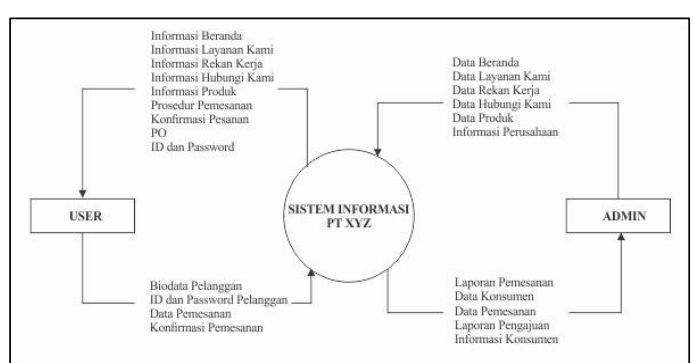

Gambar 2. Context Diagram

\section{Data Flow Diagram (DFD)}

Data flow diagram merupakan alat bantu yang dapat menggambarkan arus data di dalam sistem dengan terstruktur dan jelas. DFD Level 0 adalah diagram yang menunjukkan semua proses utama 
yang menyusun keseluruhan sistem. Diagram ini dapat dilihat pada gambar 3.

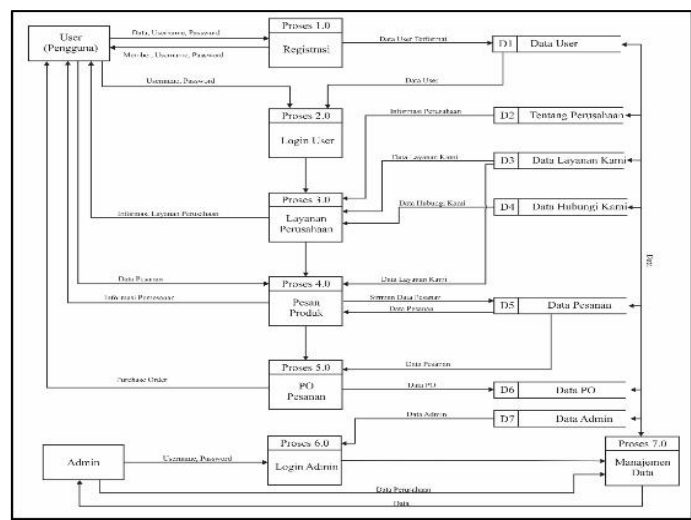

Gambar 3. DFD Level 0

\section{Use Case Diagram}

Use Case diagram adalah deskripsi fungsi dari sebuah sistem dari prespektif pengguna. Use case bekerja dengan cara mendeskripsikan tipikal interaksi antara user (pengguna) sebuah sistem dengan sistemnya sendiri melalui cerita bagaimana sebuah sistem dipakai.

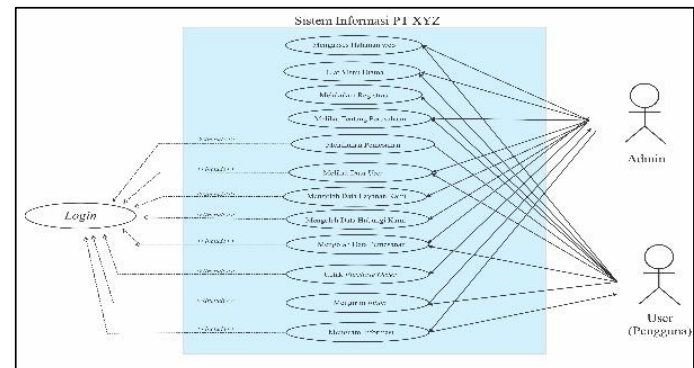

Gambar 4. Use Case Diagram

4. Struktur tabel database

Struktur yang digunakan untuk menentukan struktur dari tabel-tabel yang akan dibuat berisikan nama-nama field, type field dan ukurannya, dimana tabeltabel tersebut digunakan untuk menampung data.

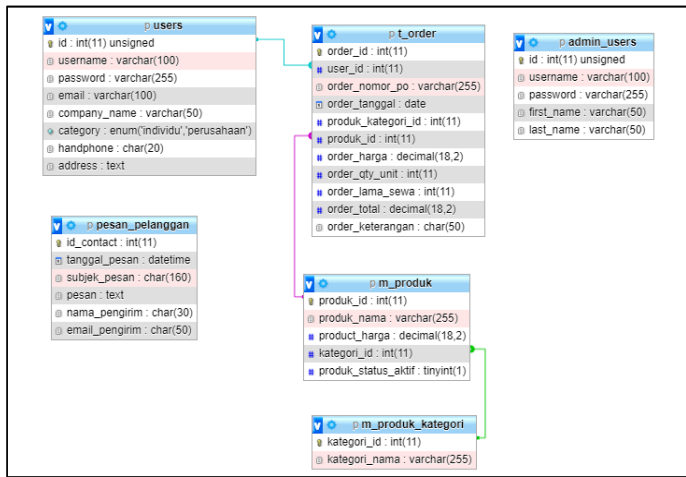

Gambar 5. Struktur Tabel

\section{Desain User Interface}

Perancangan antar muka merupakan tahapan untuk membuat tampilan atau desain dari sistem yang akan dibuat. Perancangan antar muka pemakai sangat penting untuk memenuhi kriteria yang mudah digunakan, menarik dan nyaman digunakan oleh pemakai. Dalam pembuatan rancangan user interface peneliti menggunakan aplikasi desain grafis yakni Corel Draw 2017. Adapun desain yang dibuat adalah desain untuk:

1. Halaman beranda,

2. Halaman produk,

3. Halaman profil perusahaan,

4. Halaman kontak perusahaan,

5. Halaman pemesanan,

6. Halaman rekan kerja, dan

7. Halaman admin. 
Jerio Madre, H. Yudi Sukmono, dan Suwardi Gunawan. Perancangan Sistem Informasi Berbasis Website Sebagai Salah Satu Media Promosi Pada Perusahaan

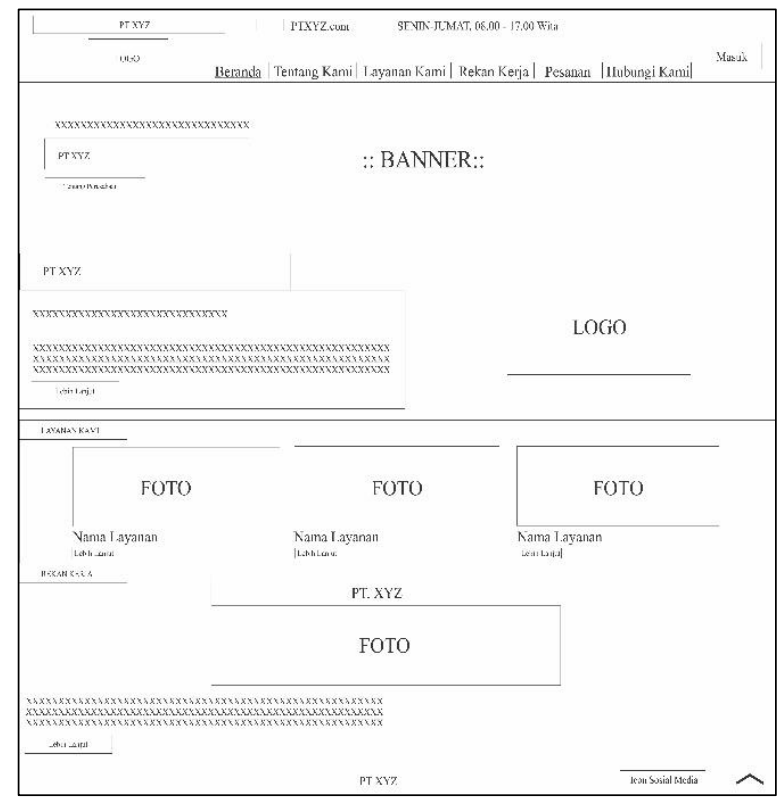

Gambar 6. Desain awal halaman utama

D. Pengkodingan (Implementasi Sistem) Tahap implementasi sistem merupakan proses yang dilakukan setelah tahap perancangan sistem selesai dilaksanakan. Tujuan yang dicapai pada tahap ini adalah dapat dioperasikannya hasil perancangan sistem yang telah dibuat dimana pada tahap ini peneliti menggunakan perangkat keras dan lunak yang telah dijabarkan sebelumnya untuk membuat coding dari rancangan ini. Pada pembuatan program digunakan framework Codeigniter 3 dengan template dan bahasa program PHP (PHP: Hypertext Prepocessor), Codeginiter digunakan agar mempermudah dalam mendokumentasikan program secara tersturuktur.

\section{E. Pengujian Black Box}

Pengujian Sistem Menggunakan Black Box Menurut Shalahuddin dan Rosa (2011), black box testing adalah menguji perangkat lunak dari segi spesifikasi fungsional tanpa menguji desain dan kode program. Pengujian dimaksudkan untuk mengetahui apakah fungsi-fungsi, masukan, dan keluaran dari perangkat lunak sesuai dengan spesifikasi yang dibutuhkan. Berikut hasil pengujian menggunakan Black Box.

Tabel 1.Tabel Uji Blackbox

\begin{tabular}{|c|c|c|c|}
\hline No. & $\begin{array}{c}\text { Skenario } \\
\text { Pengujian }\end{array}$ & $\begin{array}{c}\text { Hasil Yang } \\
\text { diharapkan }\end{array}$ & Hasil \\
\hline 1. & $\begin{array}{l}\text { Membuka } \\
\text { halaman } \\
\text { dengan } \\
\text { mengklik } \\
\text { pilihan } \\
\text { "Hubungi kami" } \\
\text { pada menu } \\
\text { header. }\end{array}$ & $\begin{array}{l}\text { Sistem akan } \\
\text { masuk ke } \\
\text { halaman } \\
\text { "Hubungi } \\
\text { kami" }\end{array}$ & Berhasil \\
\hline 2. & $\begin{array}{l}\text { Mengisi semua } \\
\text { isian data dan } \\
\text { klik Tombol } \\
\text { Kirim }\end{array}$ & $\begin{array}{l}\text { Sistem akan } \\
\text { menerima } \\
\text { dan mere-log } \\
\text { halaman } \\
\text { tanpa ada } \\
\text { pesan "error" }\end{array}$ & Berhasil \\
\hline 3. & $\begin{array}{l}\text { Salah satu isian } \\
\text { data } \\
\text { dikosongkan } \\
\text { dan klik tombol } \\
\text { kirim }\end{array}$ & $\begin{array}{l}\text { Sistem akan } \\
\text { menerima } \\
\text { dan } \\
\text { menampilkan } \\
\text { pesan "Error" }\end{array}$ & Berhasil \\
\hline 4. & $\begin{array}{l}\text { Membuka } \\
\text { halaman } \\
\text { dengan } \\
\text { mengklik } \\
\text { pilihan } \\
\text { "Beranda" pada } \\
\text { header. }\end{array}$ & $\begin{array}{l}\text { Sistem akan } \\
\text { masuk ke } \\
\text { halaman } \\
\text { "Beranda" }\end{array}$ & Berhasil \\
\hline 5. & $\begin{array}{l}\text { Membukan } \\
\text { Halaman } \\
\text { tentang kami } \\
\text { dengan } \\
\text { mengklik menu } \\
\text { "Lebih Lanjut" } \\
\text { dibawah } \\
\text { penjelasan } \\
\text { tentang } \\
\text { perusahaan. }\end{array}$ & $\begin{array}{|lr|}\text { Sistem } & \text { akan } \\
\text { masuk r } & \text { ke } \\
\text { halaman } & \\
\text { "Tentang } & \\
\text { Kami" } & \end{array}$ & Berhasil \\
\hline 6. & $\begin{array}{l}\text { Membukan } \\
\text { Halaman } \\
\text { Layanan kami } \\
\text { (Kendaraan } \\
\text { tambang) } \\
\text { dengan } \\
\text { mengklik "Lebih } \\
\text { Lanjut" pada } \\
\text { penjelasan } \\
\text { layanan kami. }\end{array}$ & \begin{tabular}{|lr} 
Sistem akan \\
masuk ke \\
halaman \\
produk \\
"Layanan \\
Kami \\
(Kendaraan \\
Tambang)"
\end{tabular} & Berhasil \\
\hline
\end{tabular}




\begin{tabular}{|c|c|c|c|}
\hline No. & $\begin{array}{c}\text { Skenario } \\
\text { Pengujian }\end{array}$ & $\begin{array}{c}\text { Hasil Yang } \\
\text { diharapkan }\end{array}$ & Hasil \\
\hline 7. & $\begin{array}{l}\text { Membukan } \\
\text { Halaman } \\
\text { Layanan kami } \\
\text { (Solar Industri) } \\
\text { dengan } \\
\text { mengklik "Lebih } \\
\text { Lanjut" pada } \\
\text { penjelasan } \\
\text { layanan kami. }\end{array}$ & $\begin{array}{l}\text { Sistem akan } \\
\text { masuk ke } \\
\text { halaman } \\
\text { produk } \\
\text { "Layanan } \\
\text { Kami (Solar } \\
\text { Industri)" }\end{array}$ & Berhasil \\
\hline 8. & $\begin{array}{l}\text { Membukan } \\
\text { Halaman } \\
\text { Layanan kami } \\
\text { (Kapur Tohor) } \\
\text { dengan } \\
\text { mengklik "Lebih } \\
\text { Lanjut" pada } \\
\text { penjelasan } \\
\text { layanan kami. }\end{array}$ & $\begin{array}{l}\text { Sistem akan } \\
\text { masuk ke } \\
\text { halaman } \\
\text { produk } \\
\text { "Layanan } \\
\text { Kami (Kapur } \\
\text { Tohor)" }\end{array}$ & Berhasil \\
\hline 9. & $\begin{array}{l}\text { Membukan } \\
\text { Halaman } \\
\text { tentang kami } \\
\text { dengan } \\
\text { mengklik menu } \\
\text { "Lebih Lanjut" } \\
\text { dibawah } \\
\text { penjelasan } \\
\text { rekan kerja. }\end{array}$ & $\begin{array}{l}\text { Sistem akan } \\
\text { masuk ke } \\
\text { halaman } \\
\text { "Rekan kerja" }\end{array}$ & Berhasil \\
\hline 10. & $\begin{array}{l}\text { Membuka } \\
\text { halaman dengan } \\
\text { mengklik } \\
\text { pilihan "Login" } \\
\text { pada header. }\end{array}$ & $\begin{array}{l}\text { Sistem akan } \\
\text { masuk ke } \\
\text { halaman } \\
\text { "Login" dan } \\
\text { menampilkan } \\
\text { isian } \\
\text { username } \\
\text { dan } \\
\text { password. }\end{array}$ & Berhasil \\
\hline 11. & $\begin{array}{lr}\text { Mengisi } & \text { semua } \\
\text { isian } & \text { data } \\
\text { dengan } & \text { data } \\
\text { akun } & \text { yang } \\
\text { sudah } & \text { terdaftar } \\
\text { pada halaman } \\
\text { "Login" dan klik } \\
\text { tombol login. }\end{array}$ & $\begin{array}{l}\text { Sistem akan } \\
\text { menerima } \\
\text { dan } \\
\text { mengarahkan } \\
\text { kembali ke } \\
\text { halaman } \\
\text { beranda } \\
\text { dengan } \\
\text { keterangan } \\
\text { login } \\
\text { berubah } \\
\text { menjadi } \\
\text { nama } \\
\text { pengguna } \\
\text { yang sedang } \\
\text { aktif. }\end{array}$ & Berhasil \\
\hline
\end{tabular}

\begin{tabular}{|c|l|l|l|}
\hline No. & \multicolumn{1}{|c|}{$\begin{array}{c}\text { Skenario } \\
\text { Pengujian }\end{array}$} & $\begin{array}{c}\text { Hasil Yang } \\
\text { diharapkan }\end{array}$ & Hasil \\
\hline 12. & $\begin{array}{l}\text { Mengisi semua } \\
\text { isian data } \\
\text { dengan data } \\
\text { akun yang } \\
\text { belum terdaftar } \\
\text { pada halaman } \\
\text { "Login" dan klik } \\
\text { tombol login. }\end{array}$ & $\begin{array}{l}\text { Sistem akan } \\
\text { menolak dan } \\
\text { menampilkan } \\
\text { pesan }\end{array}$ & Berror"' \\
\hline 13. & $\begin{array}{l}\text { Mengosongkan } \\
\text { salah } \\
\text { satu/semua } \\
\text { isian pada } \\
\text { halaman "Login" } \\
\text { dan klik tombol } \\
\text { login. }\end{array}$ & $\begin{array}{l}\text { Sistem akan } \\
\text { menolak dan } \\
\text { penampilkan "Error" }\end{array}$ & Berhasil \\
\hline
\end{tabular}

\section{KESIMPULAN}

Berdasarkan hasil penelitian maka dapat ditarik kesimpulan sebagai berikut: 1. Berdasarkan identifikasi permasalahan pada perusahan, kegiatan promosi yang dilakukan oleh PT XYZ saat ini masih kurang dikelolah dengan maksimal. Dengan dirancangnya sebuah website sebagai salah satu sarana media promosi untuk memudahkan customer menemukan dan memperoleh informasi dari perusahaan. Adapun dalam perancangan sistem informasi ini peneliti melakukan pengumpulan data tentang kebutuhan pengguna (user requirement) dengan menggunakan metode wawancara langsung terhadap pihak perusahaan. Hal yang dilakukan adalah menganalisis kebutuhan dan mengidentifikasi segala kebutuhan dan dari hasil analisis tersebut dapat ditetapkan tujuan perancangan, pengajuan usulan solusi yang dapat diterima. Pada tahap ini hal yang dilakukan antara lain:

a. Menganalisa sistem yang sedang berjalan pada tempat penelitian,

b. Mengidentifikasi kebutuhan fungsional dan non-fungsional dari rancangan yang akan dibuat, 
Jerio Madre, H. Yudi Sukmono, dan Suwardi Gunawan. Perancangan Sistem Informasi Berbasis Website Sebagai Salah Satu Media Promosi Pada Perusahaan

c. Melakukan identifikasi masalah yang terjadi pada PT XYZ, dan

d. Memberikan usulan berupa penyelesaian masalah berdasarkan dari kebutuhan perusahaan

2. Berdasarkan masalah-masalah pada perusahaan dalam hal promosi maka dilakukan perancangan sistem informasi berbasis website pada PT XYZ sesuai dengan kebutuhan perusahaan. Setelah kebutuhan perusahaan didapatkan, kemudian dilakukan desain sistem untuk menjelaskan seperti apa gambaran sistem yang akan dibuat. Website ini dirancang dengan metode prototype dengan perancangan dan desain aplikasi serta alur proses sistem yang menggunakan berbagai diagram seperti, context diagram, DFD dan use case diagram serta dilakukan pembuatan tabel database. Selanjutnya dilakukan desain tampilan dengan menggunakan aplikasi coreldraw. Setelah rancangan disepakati kemudian dilanjutkan dengan pembuatan program menggunakan framework Codeigniter 3, Bootstrap 4 dan aplikasi MySQL untuk database. Setelah program jadi, maka dilakukan pengujian dengan black box dan peningkatan performa dengan menggunakan SEO website analyzer kemudian dievaluasi dan diberikan kepada perusahaan.

Berdasarkan dari penelitian ini, maka ada beberapa saran yang diharapkan dapat diterima oleh semua pihak yang bersangkutan. Saran dapat dilihat sebagai berikut:

1. $\quad$ Dari rancangan website yang sudah dibuat, ini masih banyak kekurangan atau belum sempurna dari segi fitur, sehingga masih banyak yang harus dilakukan untuk pengembangan dan penyempurnaan sistem informasi ini, seperti menambahkan fitur sesuai dengan website yang sedang tren saat ini dan sebagainya.

2. Diharapkan kedepannya dilakukan pegembangkan website menjadi versi mobile application (IOS/Android) untuk memudahkan pelanggan mencari informasi perusahaan dan memudahkan admin dalam melakukan pengecekan pemesanan via mobile.

3. Penelitian berikutnya diharapkan dapat melakukan survey atau melakukan pengujian terhadap pelanggan untuk mengetahui respon pelanggan terhadap website ini untuk mengetahui kesesuaian dengan target konsumen dari perusahaan.

\section{DAFTAR PUSTAKA}

Amar, A. A, Yuli. \& Ambarsari N. (2015). Pengembangan Web E-Commerce Bojana Sari Menggunakan Prototype. Jurnal Program Studi Sistem Informasi Universitas Telkom. eProceeding of Engineering. 2(1): 1042-1056.

Asosiasi Penyelenggara Jasa Internet. (2018). Penetrasi Pengguna Internet di Indonesia Tahun 2018 [Daring]. Tersedia pada:https://apjii.or.id/content/read/39/41

0/Hasil-Survei-Penetrasi-dan-PerilakuPengguna-Internet-Indonesia-2018.html.

Firman, A. Wowor, H. F. \& Najoan, X. (2016). Sistem Informasi Perpustakaan Online Berbasis Web. E-journal Teknik Elektro dan Komputer. $5(2)$.

Hani, S. \& Wibowo, A.P. (2019). Rancang Bangun Website E-Commerce Pada Toko Furniture (Studi Kasus: King Akor's Sragen). Tugas Akhir thesis. University of Technology Yogyakarta.

Ishak, I. \& Simin, N. S. (2016). Sistem Informasi Profil Berbasis Web Sebagai Media Promosi Pada Waterboom Kota Ternate. Indonesia Journal on Information System. 1(01).

Jauhari, J. (2010). Upaya Pengembangan Usaha Kecil dan Menengah (UKM) dengan Memanfaatkan E-Commerce. Jurnal Sistem Informasi. 6(1):159-168.

Karolina. Dkk. (2013). Perancangan Strategi Pemasaran Berbasis Perilaku Konsumen di 
toko Swiss jaya, Jember. Jurnal Ilmiah Mahasiswa Universitas Surabaya. 2(1).

Khazim, A.I. (2016). Pengaruh strategi Internet Marketing Terhadap Perilaku Konsumen Lazada.Co.Id Dalam Berbelanja Online Melalui Variabel Electronic Word of Mouth (EWOM). Jurnal Ilmiah Ekonomi Bisnis. 21(2).

Muslim, B. \& Dayana, L. (2016). Sistem Informasi Peraturan Daerah (PERDA) Kota Pagar Alam Berbasis Web. Jurnal BETRIK. 7(1).

Rianto, B. (2018). Perancangan Sistem Infomasi Pemasaran Kerajinan Tangan Khas Inhil Berbasis Web. Studi Kasus: Dekrasnasda Kabupaten Indragiri Hilir Tembilahan Riau. Journal Computer Science vol. 4(1): 67-75.

Richard, S. (2014). Sistem Informasi Pengolahan Data IKPM (Ikatan Keluarga Pelajar Mahasiswa Muara Enim Berbasis Web Menggunakan PHP dan My Sql. Jurnal Script. 2(1): 28.
Saputra, A. (2012). Sistem Informasi Nilai akademik untuk panduan Skipsi, Penerbit Pt Elex Media Komputindo, Jakarta.

Sidharta, I. \& Mirnawati. (2015). Perancangan dan Implementasi sistem Informasi urunan Desa (Urdes) Berdasarkan Pada Pajak Bumi dan Bangunan, Jurnal Computech \& Bisnis. 9(2): 95-107.

Susilawati H. \& Wiharso, T. A. (2019). Perancanganan Aplikasi Kalkulator SParameter Berbasis Android. Jurnal Algoritma. 16(2): 120-129.

Sembiring, Z, Susilawati, Polewangi, Y.D (2021). Penerapan Marketing Berbasis Online dalam Meningkatan Omset Usaha pada UKM Karya Cipta Lestari di Desa Wonosari Kabupaten Deli Serdang. Pelita Masyarakat 3(1), 55-65 